\title{
EGFR wild-type amplification and activation promote invasion and development of glioblastoma independent of angiogenesis
}

\author{
Krishna M. Talasila • Anke Soentgerath • Philipp Euskirchen · Gro V. Rosland · Jian Wang • Peter C. Huszthy • \\ Lars Prestegarden · Kai Ove Skaftnesmo • Per Øystein Sakariassen • Eskil Eskilsson • Daniel Stieber • \\ Olivier Keunen • Narve Brekka • Ingrid Moen · Janice M. Nigro • Olav K. Vintermyr • Morten Lund-Johansen • \\ Simone Niclou $\cdot$ Sverre J. Mørk $\cdot$ Per Øyvind Enger $\cdot$ Rolf Bjerkvig $\cdot$ Hrvoje Miletic
}

Received: 23 July 2012/Revised: 24 January 2013/Accepted: 9 February 2013/Published online: 22 February 2013

(C) The Author(s) 2013. This article is published with open access at Springerlink.com

\begin{abstract}
Angiogenesis is regarded as a hallmark of cancer progression and it has been postulated that solid tumor growth depends on angiogenesis. At present, however, it is clear that tumor cell invasion can occur without angiogenesis, a phenomenon that is particularly evident by the infiltrative growth of malignant brain tumors, such as glioblastomas (GBMs). In these tumors, amplification or overexpression of wild-type (wt) or truncated and constitutively activated epidermal growth factor receptor (EGFR) are regarded as important events in GBM development, where the complex downstream signaling events have been implicated in tumor cell invasion, angiogenesis and proliferation. Here, we show that amplification and in particular activation
\end{abstract}

K. M. Talasila and A. Soentgerath contributed equally to this work.

Electronic supplementary material The online version of this article (doi:10.1007/s00401-013-1101-1) contains supplementary material, which is available to authorized users.

K. M. Talasila $\cdot$ A. Soentgerath $\cdot$ P. Euskirchen ·

G. V. Rosland - J. Wang - P. C. Huszthy · L. Prestegarden ·

K. O. Skaftnesmo · P. Ø. Sakariassen · E. Eskilsson ·

O. Keunen · N. Brekka I. Moen · J. M. Nigro ·

P. Ø. Enger · R. Bjerkvig · H. Miletic

Department of Biomedicine, University of Bergen,

Jonas Lies vei 91, 5009 Bergen, Norway

A. Soentgerath

Department of Neurosurgery, Hospital Cologne Merheim,

51109 Cologne, Germany

L. Prestegarden

Department of Dermatology, Haukeland University Hospital,

5021 Bergen, Norway

D. Stieber · O. Keunen $\cdot$ S. Niclou $\cdot$ R. Bjerkvig

NorLux Neuro-Oncology Laboratory, CRP-Santé,

1526 Luxembourg, Luxembourg of wild-type EGFR represents an underlying mechanism for non-angiogenic, invasive tumor growth. Using a clinically relevant human GBM xenograft model, we show that tumor cells with EGFR gene amplification and activation diffusely infiltrate normal brain tissue independent of angiogenesis and that transient inhibition of EGFR activity by cetuximab inhibits the invasive tumor growth. Moreover, stable, longterm expression of a dominant-negative EGFR leads to a mesenchymal to epithelial-like transition and induction of angiogenic tumor growth. Analysis of human GBM biopsies confirmed that EGFR activation correlated with invasive/ non-angiogenic tumor growth. In conclusion, our results indicate that activation of wild-type EGFR promotes invasion and glioblastoma development independent of angiogenesis, whereas loss of its activity results in angiogenic tumor growth.

Keywords Glioblastoma · EGFR amplification · Invasion

O. K. Vintermyr · S. J. Mørk · H. Miletic $(\square)$

Department of Pathology, The Gade Institute, Haukeland

University Hospital, Jonas Lies vei 65, 5021 Bergen, Norway

e-mail: hrvoje.miletic@biomed.uib.no

M. Lund-Johansen · P. Ø. Enger

Department of Neurosurgery, Haukeland University Hospital, 5021 Bergen, Norway

M. Lund-Johansen

Institute of Surgical Science, University of Bergen,

Jonas Lies vei 91, 5009 Bergen, Norway 


\section{Introduction}

Human glioblastoma (GBM) is the most frequent and most malignant primary brain tumor. The majority of GBMs arise de novo and are defined as primary GBMs, while the progression from lower grade astrocytomas results in secondary GBMs [34]. Primary GBMs most frequently harbor the common mutations $9 \mathrm{p}$ and $10 \mathrm{q}$ loss as well as amplification of epidermal growth factor receptor $(E G F R)$, a tyrosine kinase receptor [34]. Wild-type (wt) EGFR is amplified in 40-50\% of primary GBMs and a fraction of $E G F R$-amplified tumors in addition express the mutant variant EGFRvIII, a constitutively active receptor [60]. Signaling through the EGFR pathway is a complex process that involves tight regulation of several intracellular cell signaling networks [10]. When these regulatory networks are altered, as in cancer, they have been shown to contribute to malignant transformation and tumor progression through increased cell proliferation, angiogenesis, invasion, and metastasis [23, 37, 39, 43].

The diffuse infiltrative growth of tumor cells within the central nervous system (CNS) still represents a major problem for effective therapeutic intervention as the delivery of active therapeutic agents to the invasive tumor cells is limited by the blood-brain barrier (BBB). While factors that mediate tumor angiogenesis have been well defined $[7,25,51,56]$, the major mechanisms causing nonangiogenic, invasive tumor growth in vivo still remain elusive. This can partly be explained by the lack of representative animal models that reflect the invasive tumor growth seen in patients. To this end, we and others have shown that human GBMs, short-term cultured as multicellular biopsy spheroids, maintain the same DNA copy number as the parental tumors [14] and can, when xenotransplanted into the CNS of immunodeficient rats, grow invasively for extensive periods without switching to angiogenic tumor growth [53, 59]. Thus, in our model system there appears to be a selection toward a subpopulation of glioma cells, which is capable of initiating and sustaining tumor growth independent of angiogenesis. In the present study, we show that wtEGFR activation is associated with non-angiogenic, infiltrative tumor development both in our animal model as well as human GBMs and that inactivation of the receptor can lead to angiogenic tumor growth.

\section{Materials and methods}

Cell culture

Biopsy spheroids were prepared as described previously [5]. After 1-2 weeks in culture, spheroids with diameters between 200 and $300 \mu \mathrm{m}$ were selected for intracerebral implantation. For functional experiments with cetuximab and EGFR-CD533, spheroids with a standardized cell number were generated as described under "Lentiviral EGFR-CD533 production and infection of glioblastoma cells".

The human embryonic kidney cell line 293T (ATCC number CRL-11268) and the U87 cell line were obtained from the American Type Culture Collection (ATCC, Manassas, VA) and maintained in Dulbecco's modified eagle medium (DMEM) supplemented with $10 \%$ fetal calf serum (FCS) and $1 \%$ glutamine. All cell lines were grown at $37{ }^{\circ} \mathrm{C}$ in a humidified atmosphere of $5 \% \mathrm{CO}_{2}$.

\section{In vivo experiments}

Nude immunodeficient rats (rnu/rnu Rowett) were fed a standard pellet diet and were provided with water ad libitum. All procedures were approved by the Norwegian National Animal Research Authority. Biopsy spheroids were stereotactically implanted into the right brain hemisphere as described previously [53]. Rats were euthanized with $\mathrm{CO}_{2}$, perfused intracardially with $0.9 \% \mathrm{NaCl}$ and killed when symptoms developed.

Intracranial convection-enhanced delivery (CED) of cetuximab was started 6 weeks after tumor implantation and was given for 4 weeks. CED was performed using osmotic minipumps (Alzet mini-osmotic pump, model 2ML4, Durect Corp., Cupertino, CA), which maintain a constant flow of $2.5 \mu \mathrm{l} / \mathrm{h}$ over 28 days. Pumps were filled with the antibody at a concentration of $5 \mathrm{mg} / \mathrm{ml}$, consequently the rats received $300 \mu \mathrm{g}$ of the antibody per day. The pumps were connected to an intracranial catheter (Alzet Brain Infusion Kit 2). Pumps were placed subcutaneously at the back of the rats. The catheter tip was inserted through the same burr hole that had been created to inject the tumor cells and was placed approximately at the injection site of tumor cells. Control groups for cetuximab received pumps loaded with PBS.

For pimonidazole analysis, animals were injected with hypoxyprobe-1 (HPI, Burlington, MA) $30 \mathrm{~min}$ prior to euthanasia. Brains were removed and fixed in $4 \%$ formalin for 1-7 days, or tumors were excised and snap frozen in liquid nitrogen for protein isolation.

Immunohistochemistry

Immunohistochemistry of paraffin sections was performed as described previously [27]. The following primary antibodies were used: anti-human nestin diluted 1:200 (Millipore, Billerica, MA), anti-human sox2 diluted 1:200 (R\&D Systems, Minneapolis, MN), anti-CD31 diluted (Santa Cruz, Santa Cruz, CA), anti-wtEGFR diluted 1:500 (Santa Cruz), anti-pEGFR (Tyr1173) diluted 1:250 (Cell 
Signaling, Danvers, MA), anti-pimonidazole diluted 1:200 (HPI), anti-vWF, diluted 1:500 (DAKO), anti-angiopoietin2 diluted 1:200 (Santa Cruz), anti-EGFRvIII diluted 1:200 (clone L8A, a gift kindly provided by S. Clayton, Duke University, Durham, NC) and anti-GFP diluted 1:200 (Millipore). The H\&E and immunohistochemical stainings were analyzed on a Nikon light microscope (Nikon, Tokyo, Japan) using Nikon imaging software. The quantification of vessel area fractions was performed using the Nikon imaging software. Overview pictures of histological slides were taken using a digital slide scanner and Imagescope software (Aperio, Vista, CA).

\section{Western blotting}

Protein extraction and western blotting were performed as described previously [53]. Primary antibodies used were anti-pAkt (Ser-473) diluted 1:500 (Cell Signaling), antipStat3 (Tyr-705) diluted 1:2,000 (Cell Signaling), antipMAPK (Thr-202/Tyr-204) diluted 1:2,000 (Cell Signaling), anti-EGFR diluted 1:500 [Life Technologies (Biosource)], anti-EGFRvIII diluted 1:1,000 (clone L8A, a gift kindly provided by S. Clayton, Duke University, Durham, NC), anti-VEGF diluted 1:200 (Santa Cruz), anti-HIF-1 $\alpha$ diluted 1:500 (Becton-Dickinson, San Jose, CA), anti-angiopoietin1 diluted 1:300 (Santa Cruz), anti-angiopoietin2 diluted 1:500 (Santa Cruz), anti-FGF2 diluted 1:500 (Santa Cruz), antiCD133/1 clone AC133 diluted 1:100 (Miltenyi, BergischGladbach, Germany), anti-vimentin diluted 1:500 (DAKO), anti-snail diluted 1:100 (Abgent, San Diego, CA), anti-Twist diluted 1:100 (Santa Cruz), anti-beta-Actin diluted 1:1,000 (Abcam, Cambridge, UK) and anti-GAPDH diluted 1:2,500 (Abcam).

The primary antibody was detected using a goat $\mathrm{F}\left(\mathrm{ab}^{\prime}\right) 2$ fragment anti-rabbit $\operatorname{IgG}(\mathrm{H}+\mathrm{L})$-peroxidase diluted 1:100,000 (Beckman Coulter, Brea, CA), or goat anti mouse IgG-HRP diluted 1:25,000 (Santa Cruz) or HRPconjugated goat anti-rabbit/mouse secondary antibody (Immunotech, Fullerton, CA) diluted 1:2,500.

\section{Cloning of EGFR-CD533}

The EGFR-CD533 construct was a gift from Joseph Contessa, Yale University School of Medicine, New Haven, CT. From this plasmid, EGFR-CD533 was amplified by PCR using 5'-GCATCATCTAGAGCCACCA TGCGACCCTCCGGG- $3^{\prime}$ as forward and $5^{\prime}$-GCATCACT CGAGTCAGCGCTTCCGAACGATG-3 as reverse primer. The primers were designed to insert $\mathrm{XbaI}$ and $\mathrm{XhoI}$ restriction sites flanking the EGFR-CD533 gene. The lentiviral vector pRRL.sinCMVeGFPpre [47] was cut with XbaI and SalI to remove the eGFP gene. The PCR product was cut with $\mathrm{XbaI}$ and $\mathrm{XhoI}$ and ligated into the lentiviral vector.
Lentiviral EGFR-CD533 production and infection of glioblastoma cells

Lentiviral vectors carrying EGFR-CD533 or GFP were produced in 293T cells using FuGene HD transfection reagent (Life technologies, Paisley, UK) according to the manufacturer's instructions. The production and titration of lentiviral vectors were performed as described previously [18]. For infection, spheroids were dissociated using the Neuronal dissociation kit (Miltenyi, Bergisch-Gladbach, Germany), plated in round-bottomed 96 wells with 3,000 cells/well in culture medium with $4 \%$ methylcellulose, and infected with viral supernatants at an MOI of 5-30. 96-well plates were centrifuged for $1.5 \mathrm{~h}$ at $31^{\circ} \mathrm{C}$. Medium was changed 2 days after infection. 6 days after infection, reformed spheroids were stereotactically implanted using 10 spheroids/rat.

\section{Array $\mathrm{CGH}$}

Array CGH was performed as previously described [53].

Gene expression analysis

RNA was purified from tissue samples using Ambion Trireagent (life technologies) following the manufacturer's instructions. RNA samples were then DNAse treated using Ambions turbo DNA Free kit to remove any contaminating genomic DNA. Microarray analysis of EGFRCD533 and control animals were carried out as specified in [50].

Functional analysis of gene expression data

Data were analyzed using IPA (Ingenuity Systems, http://www.ingenuity.com). Right-tailed Fisher's exact test was used to calculate a $p$ value determining the probability that each biological function assigned to that data set is due to chance alone. Upstream regulator analysis was based on prior knowledge of expected effects between transcriptional regulators and their target genes stored in the Ingenuity ${ }^{\circledR}$ Knowledge Base. Two statistical measures, standard in IPA, were used to detect potential transcriptional regulators: an overlap $P$ value and an activation $z$ score. First, the analysis examined how many known targets of each transcriptional regulator were present in our data set, resulting in an estimation of an overlap $P$ value. We set a threshold of an overlap $P$ value $<0.05$ to identify significant upstream regulators. Second, the known effect (activation or suppression) of a transcriptional regulator on each target gene was compared with observed changes in gene expression. Based on concordance between them, an activation $z$ score was assigned, showing whether a 
potential transcriptional regulator was in "activated" ( $z$ score $>2)$, "inhibited" ( $z$ score $<-2)$ or uncertain state.

Fluorescence in situ hybridization (FISH)

FISH analyses of paraffin sections were performed with the Vysis LSI EGFR SpectrumOrange/CEP 7 SpectrumGreen probe (Abbott Molecular, Des Plaines, IL) using the DAKO Histology FISH Accessory Kit (DAKO, Glostrup, Denmark).

Magnetic resonance imaging (MRI)

Axial T1-weighted (T1w) RARE sequences and (T2w) RARE sequences were acquired as described previously [58]. Tumor volumes were calculated using a volumetric approach, where masks were created in Bruker's Paravision 5.0 software, by delineating tumor in consecutive sections of the T2-weighted images. A region growing algorithm was used to assist in finding the contours of the tumor, where the seed point was placed centrally in the tumor, and the parameters of the algorithm were optimized to include all hyperintense pixels from the tumor area.

\section{Tissue microarray}

Paraffin sections from a tissue microarray of 243 GBM patients were prepared for H\&E, immunostaining and FISH. 206 cases had sufficient material left for analyses of all markers. Scoring of stained sections was performed independently by two certified neuropathologists (SJM and HM). Scoring scheme:

1. Proportion of positive tumor cells (P): $0 \%$ (0); $1-10 \%$ (1); 11-50\% (2); >50\% (3)

2. Intensity of staining (I): negative (0); weak (1); moderate (2); strong (3)

3. Staining index $(\mathrm{SI})$ : Proportion $(\mathrm{P}) \times$ intensity $(\mathrm{I})$

The mean SI was assessed from both scorings and served as the final score displayed in the results section.

The Norwegian Data Inspectorate and the Regional Committee for Ethics in Research have approved this project. The study was performed in accordance with the Helsinki Declaration.

\section{Statistical analysis}

Survival was analyzed by a log-rank test based on the Kaplan-Meier test using SPSS software. Differences between pairs of groups were determined by the Student's $t$ test. $P$ values $<0.05$ were considered significant.

\section{Results}

Two human GBM xenograft phenotypes can be defined by different angiogenic and invasive growth properties

We rigorously characterized the histological features of intracerebral xenografts established from 12 different patients with primary GBMs. Two distinct tumor subtypes were identified based on their ability to induce angiogenesis. As described previously, tumors in the first subtype were highly invasive and showed no signs of angiogenesis (Fig. 1a, Fig. S1) [53]. In the second subtype, tumors displayed angiogenic growth characterized by dilated macrovessels and endothelial hyperplasia. In addition, the majority of tumors also displayed typical microvascular proliferations and/or pseudopalisading necrotic areas, which are angiogenic hallmarks of GBM growth (Fig. 1a, Fig. S1, Table S1). Quantification of tumor vessels using the vascular marker vWF revealed that the area fraction of vascular elements was significantly higher in the angiogenic phenotype compared to its non-angiogenic counterpart (Fig. 1b). The angiogenic and invasive phenotypes were also verified by MRI. MRI is routinely used in the clinical setting to distinguish angiogenic (glioblastoma) from nonangiogenic tumors (low grade gliomas). Contrast enhancement represents vascular permeability and is only seen in highly angiogenic tumors [3]. In our model, the angiogenic phenotype showed more demarcated tumors and contrast enhancement on MRI, while the invasive tumors showed illdefined borders and no contrast enhancement (Fig. 1c). To further compare the angiogenic and invasive phenotypes, we assessed expression of the pro-angiogenic factors VEGFA, ANGPT1, ANGPT2 and bFGF. As shown in Fig. 1d, the pro-angiogenic factors were mainly associated with the angiogenic phenotypes.

When comparing the invasive capabilities of both tumor subtypes, we found that the non-angiogenic phenotype showed extensive single cell infiltration into cortical brain areas in addition to migration into the contralateral hemisphere while tumor growth in the angiogenic phenotype was largely confined to the white matter with a more defined border and significantly fewer cells invading into the cortex (Fig. 1e, f).

Since various stem cell markers have been associated with a tumorigenic phenotype in human gliomas [30], we analyzed invasive and angiogenic xenografts for the expression of the stem cell markers nestin, sox 2 and CD133. All tumors of either phenotype showed expression of both nestin and sox 2 . However, CD133, a controversial marker for stem-like cancer cells, was expressed at low to intermediate levels in two out of three xenografts of either phenotype (Fig. S2). Thus, the expression of stem cell markers was not linked to a specific phenotype. 
a
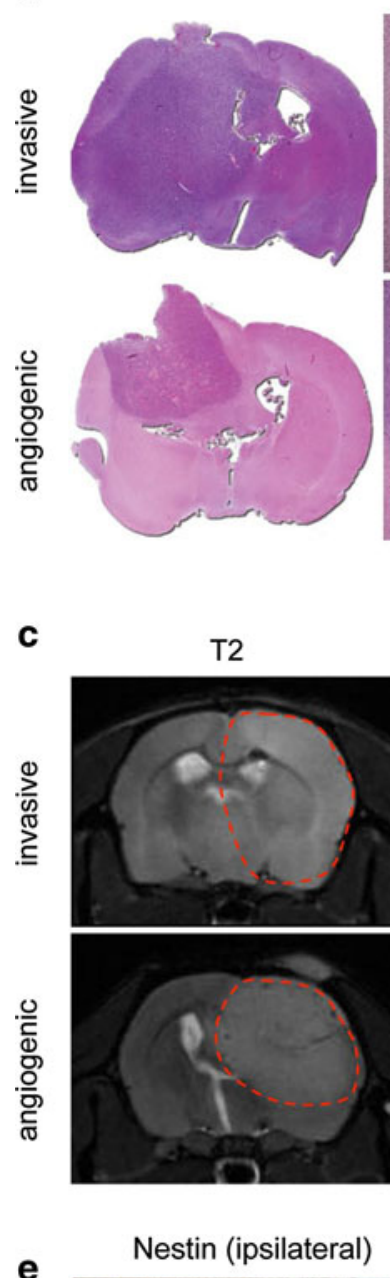

e

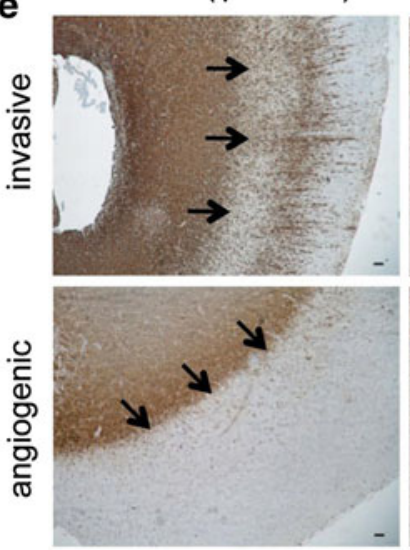

$H \& E$
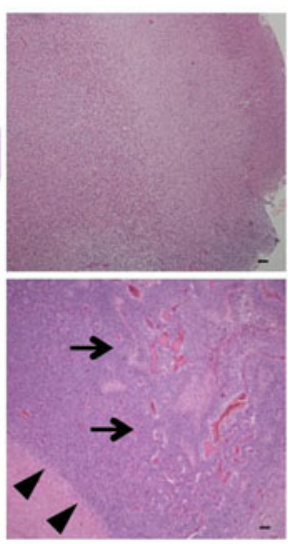

$H \& E$

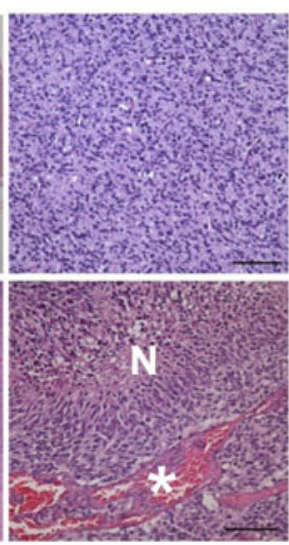

CD31

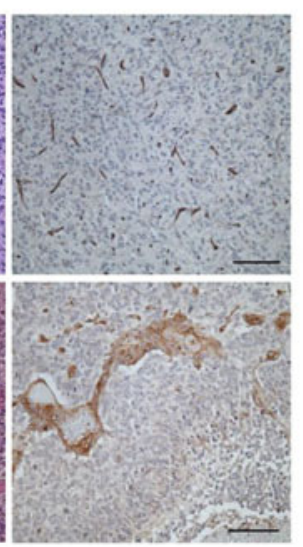

b

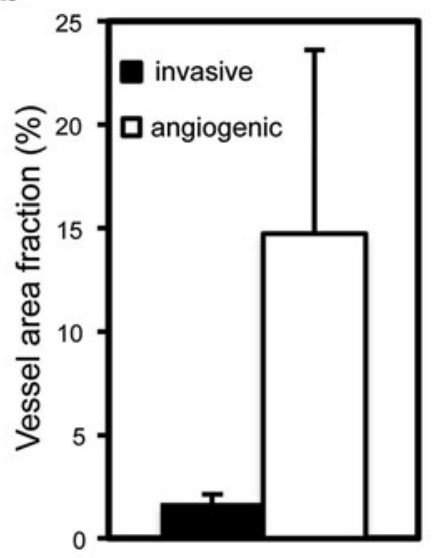

C
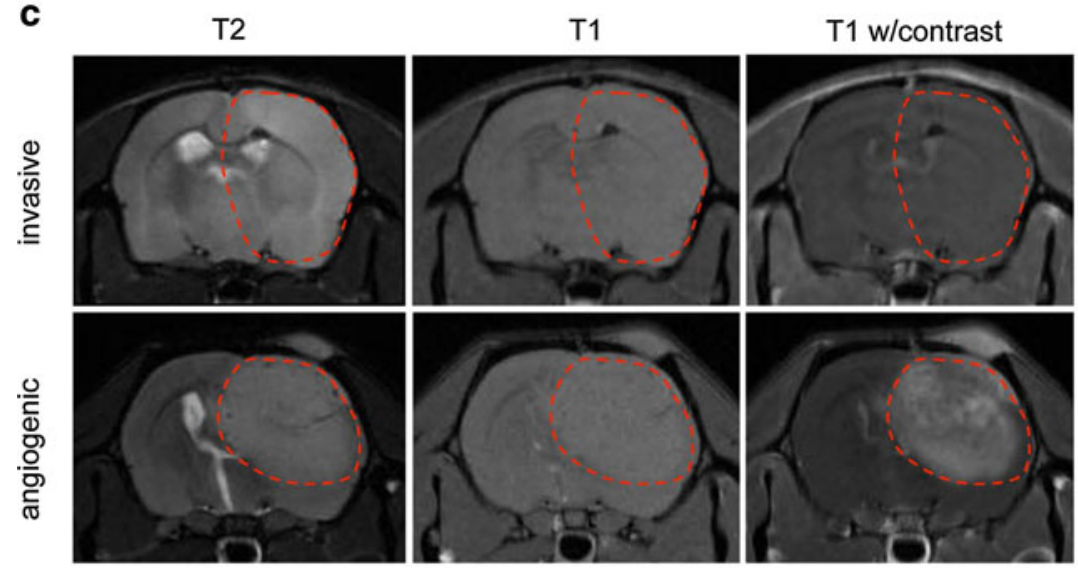

d
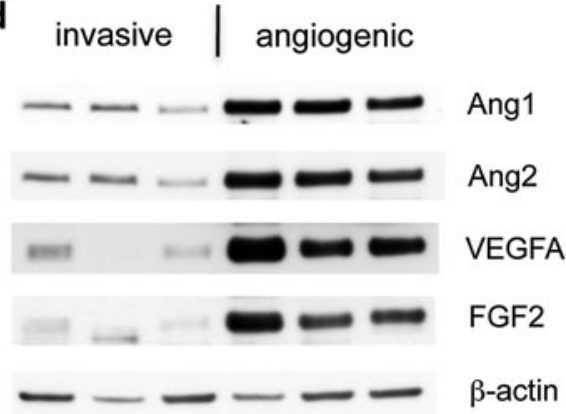

Fig. 1 Characterization of invasive, non-angiogenic and angiogenic human glioblastoma xenografts. a Hematoxylin and eosin (H\&E) and immunohistochemical staining of sections from invasive (P17) and angiogenic (P13) xenograft tumors with antibodies against CD31, an endothelial marker. Arrows point to an angiogenic area. Arrowheads show the sharp demarcation of angiogenic tumors. $N$ depicts a necrotic area and the asterisk indicates microvascular proliferation. b Area fraction of vascular elements immunostained with vWF in invasive versus angiogenic tumors from two different animals in each group. Quantification was performed at $\times 200$ magnification. $P<0.001 ; n=20$. c T2- and T1-weighted MRIs with and without f

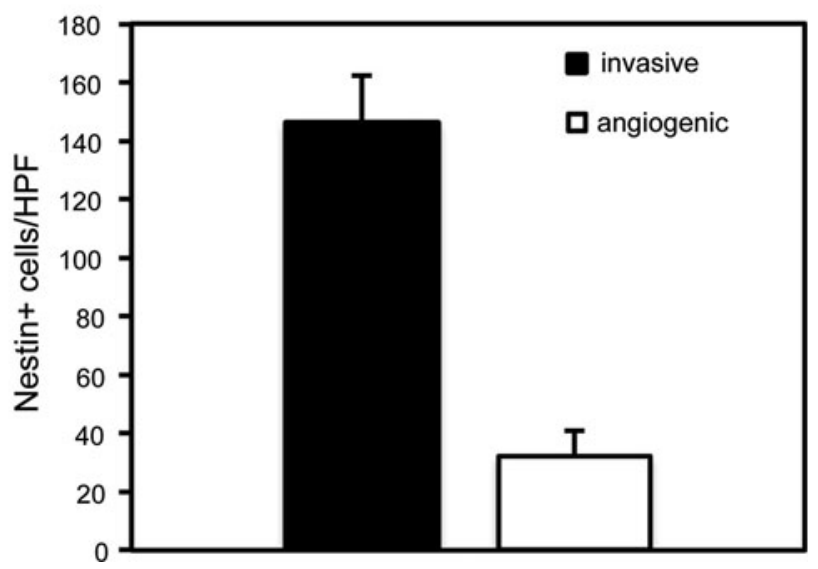

contrast show demarcated tumors with contrast enhancement in the angiogenic group (P13), while invasive tumors (P6) have ill-defined borders and no contrast enhancement. d Western blot shows high expression of angiogenic factors in angiogenic (P6, P8, P22) compared to invasive tumors (P1, P3, P13). e Immunohistochemical staining of sections from both groups with antibodies against nestin. Arrows point at the white matter/cortex border demonstrating less invasion into the cortex by angiogenic tumors. $\mathbf{f}$ Quantification of invasive cells in cortical areas from two different animals in each group. $H P F$ high microscopic view field $(\times 400$ magnification $)$. $P<0.001 ; n=10$. Values represent mean \pm SD. Scale bars $100 \mu \mathrm{m}$ 


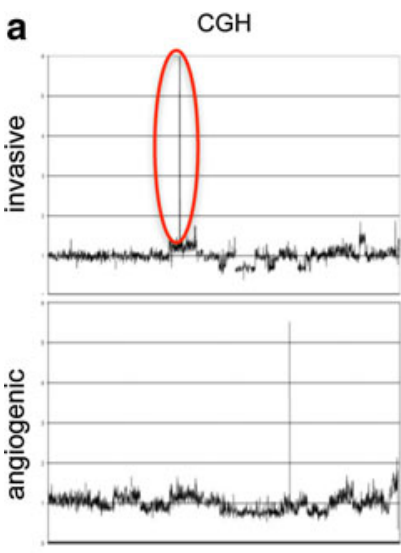

C
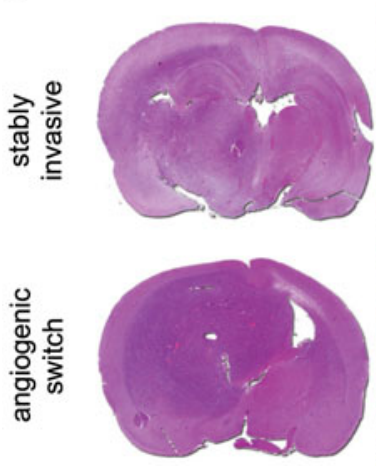

d

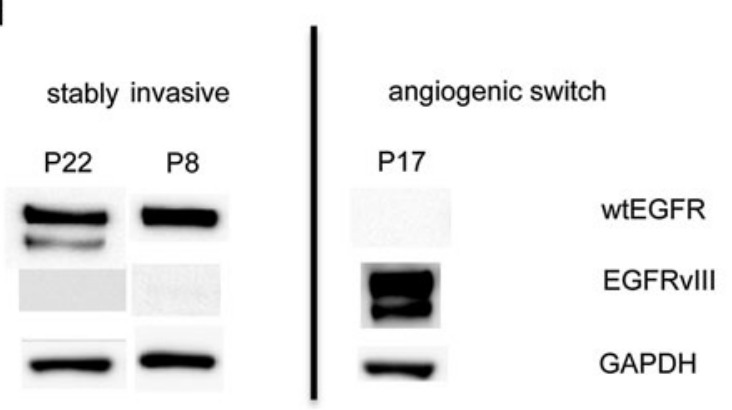

Fig. 2 EGFR amplification and activation promote non-angiogenic tumor growth in glioblastoma xenografts. a aCGH of invasive (P17) and angiogenic (P13) tumors. Red circle highlights EGFR amplification. FISH with an $E G F R /$ chromosome 7 probe in red and green, respectively and immunohistochemical staining of sections from invasive and angiogenic tumors with antibodies against wtEGFR and phosphorylated EGFR. Amplification, expression and activation of wtEGFR are present only in the invasive phenotype. b FISH with an $E G F R /$ chromosome 7 probe in red and green, respectively (patient/ xenograft labels correspond to Table 1). The majority of tumor cells in xenograft tumors show high EGFR amplification. In contrast, tumor cells from patient biopsies show variable amounts of EGFR amplification. $\mathbf{c}$ In vivo passaged EGFR-amplified tumor that stays

\section{Amplification and activation of wild-type EGFR} is associated with non-angiogenic, invasive tumor growth

To determine whether angiogenic and non-angiogenic tumors differed at the molecular level, we performed array

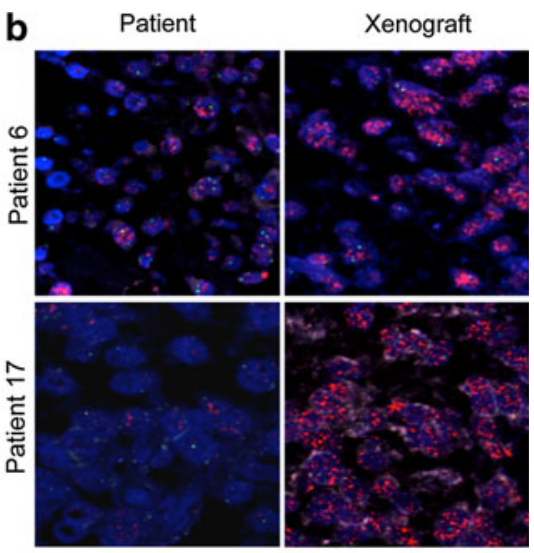

wtEGFR
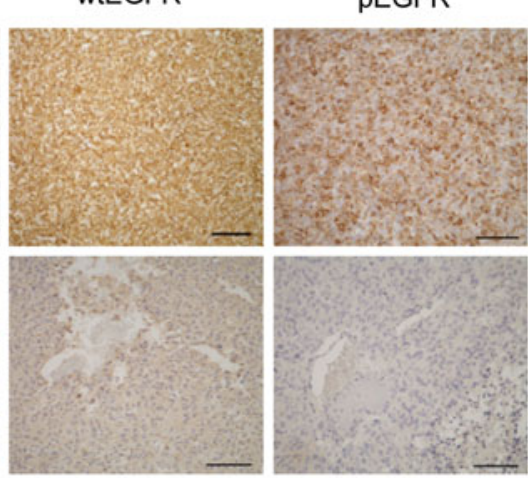

e

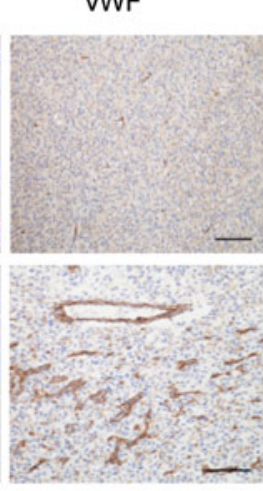

pEGFR

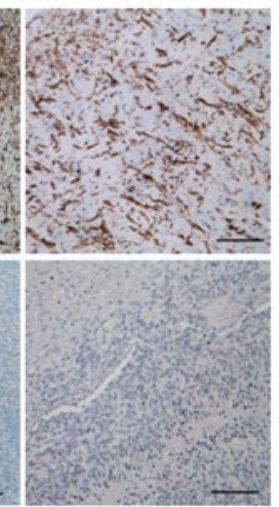

vWF

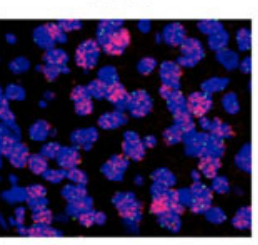

wtEGFR

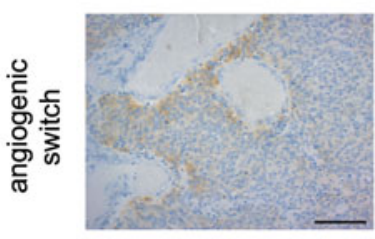

EGFRvIII

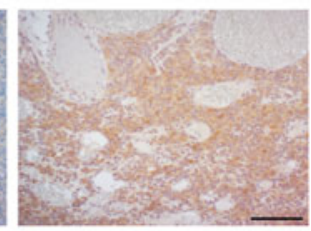

stably invasive (patient 8) shows also stable wtEGFR and pEGFR expression. In contrast, an in vivo passaged EGFR-amplified tumor that switches to angiogenesis (P17) shows downregulation of wtEGFR and pEGFR in the angiogenic center. $N$ depicts a necrotic area and the arrowheads indicate microvascular proliferation. All pictures are taken from the tumor center. Scale bars $100 \mu \mathrm{m}$. d wtEGFR and EGFRvIII western blot of stably invasive xenografts and xenografts that switch to angiogenesis (xenograft labels correspond to Table 1). EGFRvIII expression is lost in stably invasive xenografts, while it is upregulated upon the angiogenic switch. e Immunhistochemical staining with antibodies against wtEGFR and EGFRvIII. EGFRvIII is expressed in a xenograft (A3) that switches to angiogenesis, while wtEGFR is downregulated. Scale bars $100 \mu \mathrm{m}$

comparative genomic hybridization (aCGH). While this analysis revealed several common genomic changes in both groups, such as losses of chromosomes $9 \mathrm{p}$ and $10 \mathrm{q}$, amplification of EGFR occurred exclusively in the nonangiogenic, invasive phenotype (Fig. 2a; Table 1). FISH 
Table 1 Genomic and histological profile of xenografts derived from patient biopsies

\begin{tabular}{llllll}
\hline Patients & Chromosomal losses & Chromosomal gains & EGFR amplification & EGFRvIII status & Histology \\
\hline A3 & $*$ & $*$ & + & + & Highly invasive, non-angiogenic \\
A5 & $9 \mathrm{p}, 10$ & & + & $*$ & - \\
P6 & $*$ & $*$ & + & + & + \\
P8 & $6 \mathrm{q}, 9 \mathrm{p}, 10,13 \mathrm{q}, 14 \mathrm{p}, 18 \mathrm{q}$ & $7,8 \mathrm{q}$ & + & + & Angiogenic, less invasive \\
P17 & $9 \mathrm{p}, 10,13$ & 7,19 & + & - & - \\
P22 & $*$ & $*$ & + & - & - \\
P1 & & 7 & - & - & \\
P2 & $10,15 \mathrm{p}$ & & - & $*$ \\
P3 & 9,10 & 7,21 & - & - \\
P7 & $9 \mathrm{p}, 10,14,6 \mathrm{q}$ & & - & - & \\
P13 & 10 & 7 & 7 & - & \\
A1 & $9 \mathrm{p}, 10,11 \mathrm{q}$ & & & & \\
\hline
\end{tabular}

* Not determined

verified these results (Fig. 2a; Table 1), but also revealed some interesting patterns regarding the presence of EGFR amplification. High $E G F R$ amplification was detected in the tumor cells from the invasive xenografts while corresponding patient tumors showed variable levels of EGFR amplification in the tissue sections (Fig. 2 b). In our model, the wtEGFR expression was strongly associated with the amplification status of the gene. Importantly, activation (phosphorylation) of EGFR was observed in tumors with genomic EGFR amplification, while tumors without amplification lacked EGFR expression and activation (Fig. 2 a). To investigate whether there was a difference in major downstream signaling pathways of both phenotypes, we performed western blotting of pAkt, pMAPK and pStat3. These pathways were activated in both phenotypes (Fig. S3), suggesting that common genomic changes independent of EGFR are sufficient drivers of major downstream signaling events.

We have previously shown that non-angiogenic tumors can spontaneously switch to an angiogenic phenotype upon in vivo passaging [53]. To determine whether wtEGFR amplification, expression, and activation were changed during the angiogenic switch, we analyzed four EGFRamplified, non-angiogenic tumors by serial in vivo passaging. We observed that two tumors switched to an angiogenic phenotype, while the other two maintained a stable invasive phenotype (Fig. 2c). Both phenotypes harbored EGFR amplification; however, while the stably invasive tumors showed high levels of wtEGFR expression and phosphorylation (pEGFR), both proteins were downregulated in the core of tumors that switched to an angiogenic phenotype (Fig. 2c). In addition to the wtEGFR protein, various mutants exist, such as EGFRvIII [42]. However, EGFRvIII is expressed in fewer tumor cells than wtEGFR in most patient samples and amplification of
EGFRvIII occurs to a much lesser extent compared to wtEGFR [4]. By evaluating EGFRvIII in our xenografts, we found its expression only in tumors with wtEGFR amplification (Fig. S4; Table 1), suggesting a strong association between wtEGFR amplification and EGFRvIII expression which has also been described in patient biopsies [57]. Interestingly, EGFRvIII was lost in stably invasive tumors after serial in vivo passages while it was expressed in xenografts that switched to an angiogenic phenotype (Fig. 2d, e). This shows opposite regulations of wtEGFR and EGFRvIII in our xenograft system and indicates that wtEGFR expression is necessary to drive the invasive phenotype, while EGFRvIII is dispensable and might be involved in stimulating angiogenic tumor growth when wtEGFR expression is lost. The relevance of EGFRvIII for tumor angiogenesis has been previously described $[6,11,36]$.

Activation of EGFR in patient samples correlates with invasive/non-angiogenic tumor growth

As our animal model might mimic the development and progression of EGFR-amplified tumors in patients, we analyzed a tissue microarray from 206 GBM patients for $E G F R$ amplification, protein expression and activation (pEGFR). EGFR amplification was found in 87 (41.4\%) patients which is in close agreement with previous results [12]. Moderate-to-high wtEGFR expression in a significant fraction $(>10 \%$ ) of tumor cells (score $\geq 4$ ) was detected in $77(88.5 \%)$ out of 87 EGFR-amplified tumors and in 26 $(21.9 \%)$ out of 119 non-amplified tumors (Table S2). Notably, a significant fraction $(>10 \%)$ of moderate-tohigh pEGFR positive tumor cells (score $\geq 4$ ) was exclusively found in amplified tumors with high EGFR expression (score $\geq 4$ ). However, only $22(25.3 \%)$ of 87 
a

H\&E
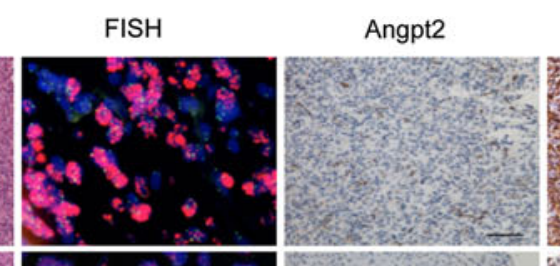

wtEGFR

pEGFR
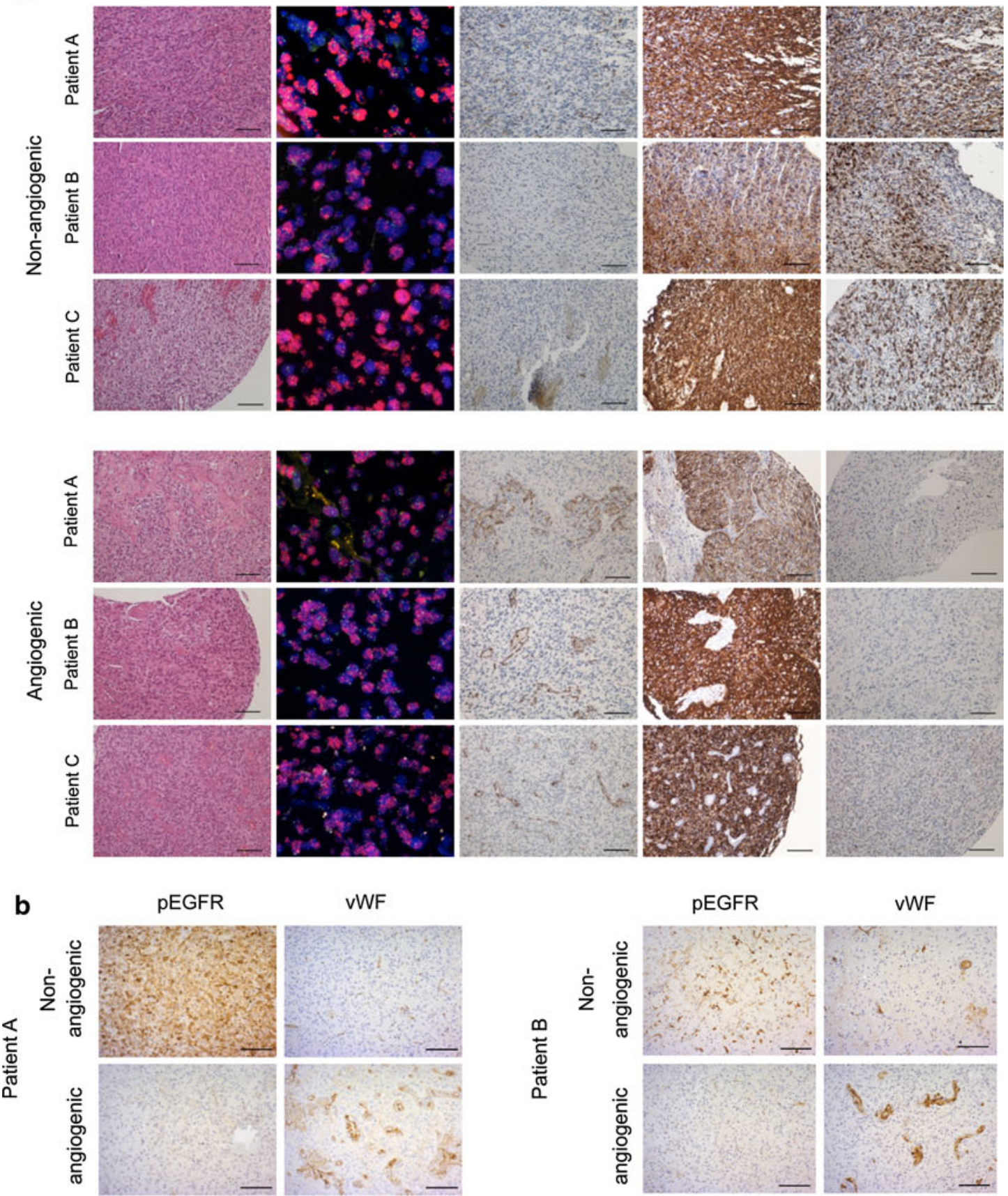

vWF
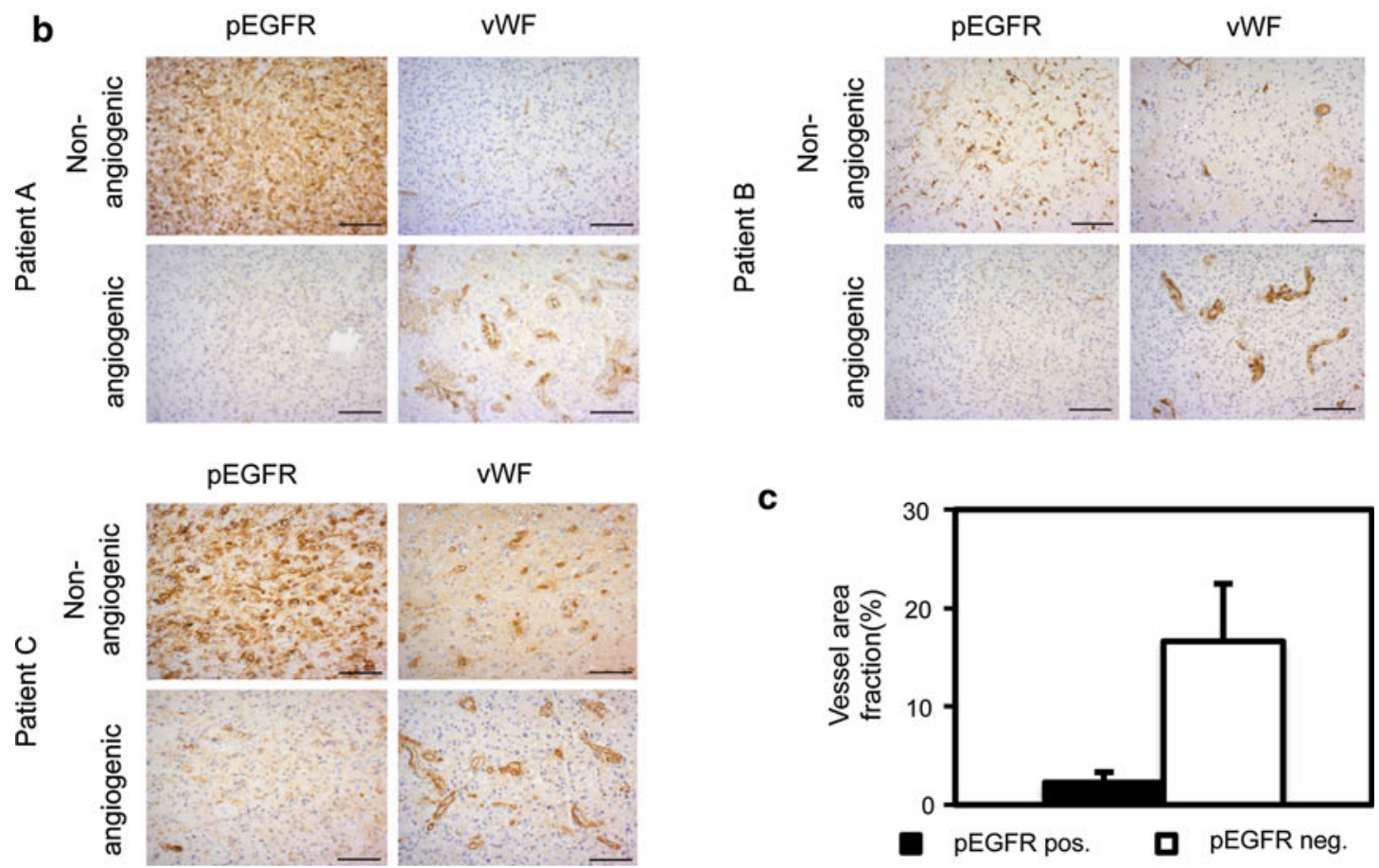

C
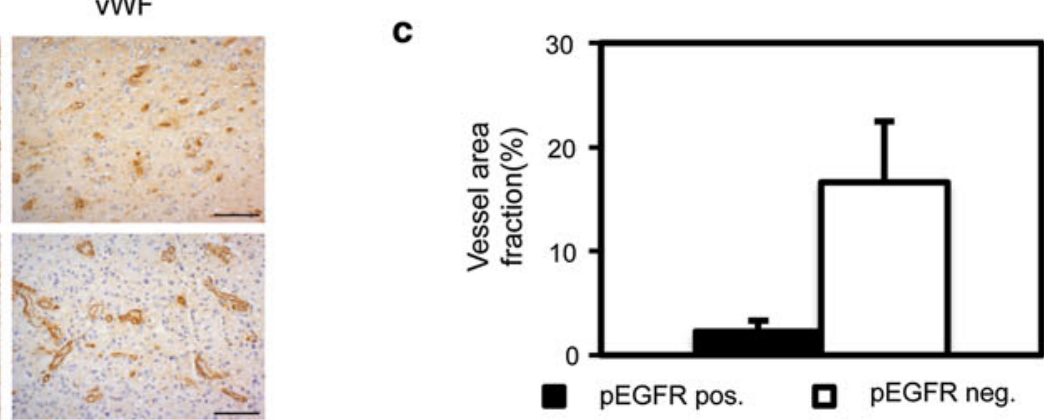
Fig. 3 EGFR activation promotes invasive/non-angiogenic tumor growth in GBM patient biopsies. Tissue microarray (TMA) of GBM biopsies. a $E G F R$-amplified GBM biopsies as verified by FISH with an $E G F R /$ chromosome 7 probe in red and green, respectively. $\mathrm{H} \& \mathrm{E}$ sections and angiopoietin2 stainings indicate non-angiogenic (upper panel) versus angiogenic areas (lower panel) in EGFR-amplified tumors. High pEGFR expression is only found in non-angiogenic areas (upper panel). b Immunohistochemical staining of pEGFR positive biopsies selected from the TMA with antibodies against pEGFR and vWF. pEGFR positive tumor areas are non-/less angiogenic compared to angiogenic, pEGFR negative areas within the same biopsies. Scale bars $100 \mu \mathrm{m}$. c Area fraction of vascular elements immunostained with vWF from pEGFR positive versus angiogenic, pEGFR negative areas from five different patients. Quantification was performed at $\times 200$ magnification. $P<0.001$; $n=10$. Values represent mean $\pm \mathrm{SD}$

amplified tumors had this moderate-to-high pEGFR (score $\geq 4$ ), suggesting that activated EGFR is confined to a subpopulation within EGFR-amplified tumors (Table S2). Cells with activated EGFR were found in non-angiogenic or invasive areas where angiogenic vessels were rarely detected (Fig. 3a, upper panel). In contrast, angiogenic biopsies from EGFR-amplified tumors with abnormal vessels and high angiopoietin-2 levels showed only a few single or no EGFR-activated cells (Fig. 3a, lower panel). The expression of wtEGFR did not show the same association to invasiveness as pEGFR (Fig. 3a) suggesting that the activation of EGFR, rather than absolute levels of EGFR protein, is the most important factor determining non-angiogenic tumor growth. In addition, we analyzed in detail whole biopsy tissues from seven patients that had moderate-to-high pEGFR expression (score $\geq 4$ ). To verify that pEGFR positive areas were non-angiogenic/ invasive, we compared these areas to angiogenic areas from the same biopsies. Indeed, pEGFR positive areas had smaller vessels that covered significantly smaller area fractions of the tumor tissue, compared to $\mathrm{pEGFR}$ negative, angiogenic areas (Fig. 3b, c, Fig. S5). Thus, the activation of EGFR correlated with non-angiogenic, invasive growth in both the animal model and in patient biopsies.

Cetuximab inhibits tumor growth and invasion of EGFR-amplified xenografts

To functionally verify that activation of EGFR is driving invasion in human GBM, we used a clinically relevant antiEGFR antibody, cetuximab, to block wtEGFR activation in the stably invasive, EGFR-amplified xenografts. To ensure drug delivery to the invasive cells across the BBB, we used a CED technique [22], which leads to a broad distribution of compounds within the brain as described previously [19]. We delivered cetuximab to tumors 6 weeks after tumor implantation using osmotic minipumps. After 4 weeks of continuous cetuximab administration, we observed a dramatic effect on tumor growth and invasion as evidenced by MRI and histology (Fig. 4). The treated tumors were significantly smaller $\left(125.75 \mathrm{~mm}^{3}\right)$ compared to control tumors $\left(810 \mathrm{~mm}^{3}\right)$ (Fig. $\left.4 \mathrm{a}, \mathrm{b}\right)$, which caused neurological symptoms at this stage. Reflecting a slower growth rate, the proliferative activity of treated tumors was significantly lower compared to the controls (Fig. 4c). Importantly, there was a significant block of invasion into the brain in the treatment group, which was most pronounced proximal to the injection site, where tumors showed a demarcated border (Fig. 4d, e). In contrast, the same area in control tumors showed a prominent invasion of tumor cells (Fig. 4d, e). Distal to the injection site, tumor cells in the treatment group showed gradually increased invasiveness, yet infiltration was substantially less compared to control tumors (Fig. 4d, e). This effect might be explained by a lower concentration of cetuximab distal to the injection site. Upon terminating cetuximab administration, the tumors were followed up for two additional weeks. This revealed a reversion to the invasive phenotype similar to what was seen in control tumors (Fig. 4d, e). Thus, these data show that a continuous inhibition of wtEGFR activation is necessary to inhibit GBM invasion.

Stable inactivation of EGFR by a dominant-negative receptor induces an angiogenic switch in EGFR-amplified xenografts

As cetuximab treatment was transient and performed on established tumors, we chose an additional method to stably block wtEGFR activation in the majority of tumor cells through the whole period of tumor development and progression. Using lentiviral vectors, we genetically modified EGFR function by introducing an inactive mutant of the receptor in EGFR-amplified tumors. This construct downregulates EGFR signaling in a dominant-negative manner (EGFR-CD533) [13]. Prior to implantation, tumor cells were mock infected, infected with a lentiviral GFP control vector or with a lentiviral EGFR-CD533 construct. Expression of dominant-negative EGFR protein was verified by western blot of tumor tissue (Fig. 5a). Notably, the expression of wtEGFR was strongly downregulated in the dominant-negative group compared to the control tumors (Fig. 5a, Fig. S6).

Kaplan-Meier analysis showed a significantly prolonged survival of animals in the EGFR-CD533 group compared to the control group (Fig. 5b; log-rank: $P<0.05$ ), indicating a slower development of the modified tumors. To assess the tumor growth characteristics, we performed MRI. The images revealed circumscribed, contrastenhancing tumors in the EGFR-CD533 group, while controls showed highly invasive, non-enhancing lesions (Fig. 5c, Fig. S6). The MRI findings were confirmed both 

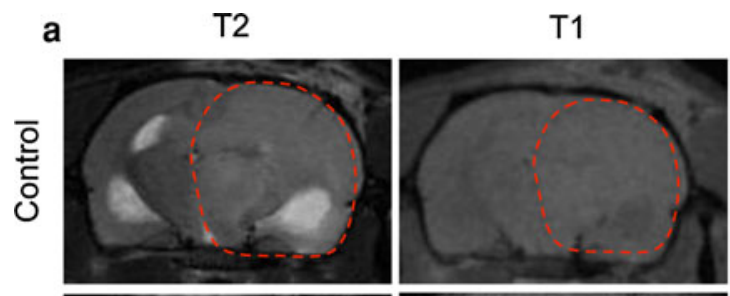

T1 w/ contrast
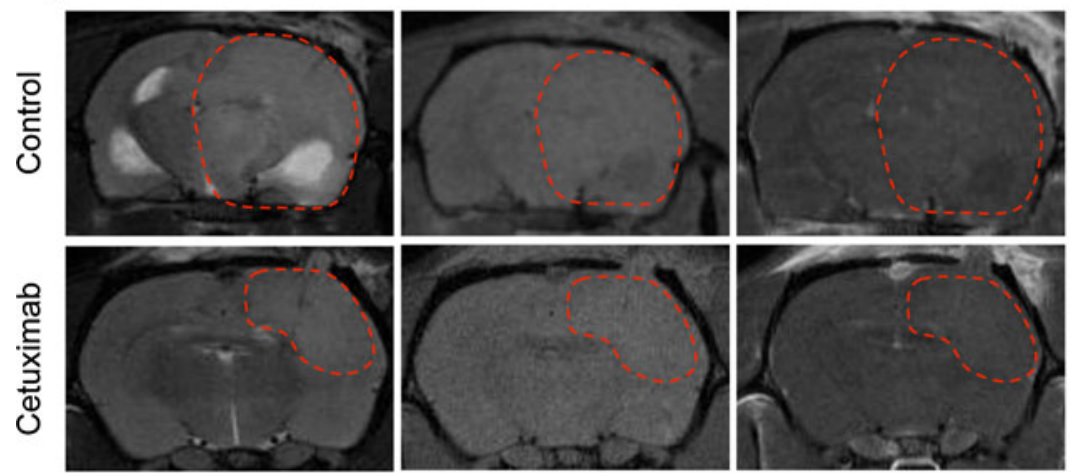

c

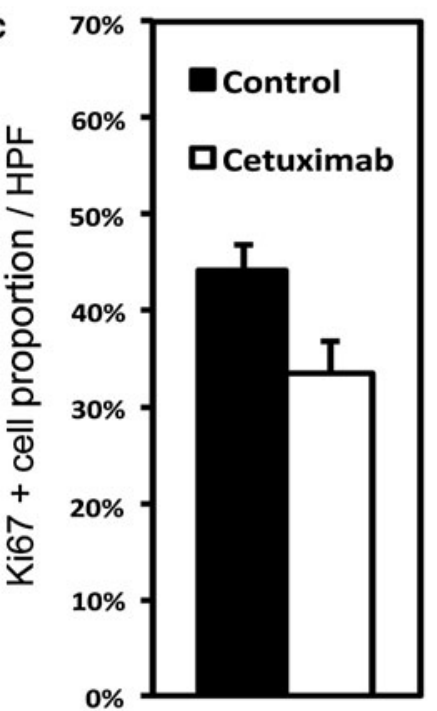

d

d
은
음

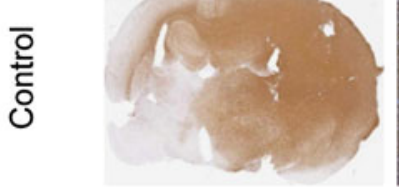

를

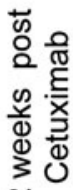

Overview
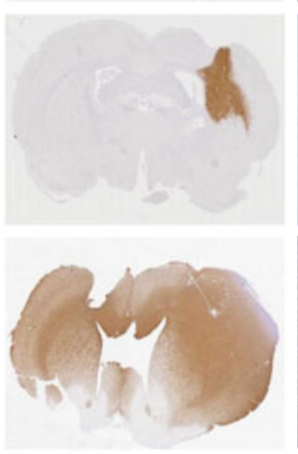

b

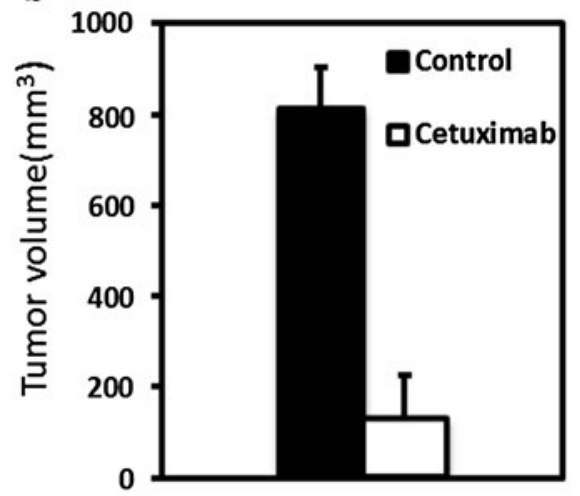

Proximal to I.S.

Distal to I.S.
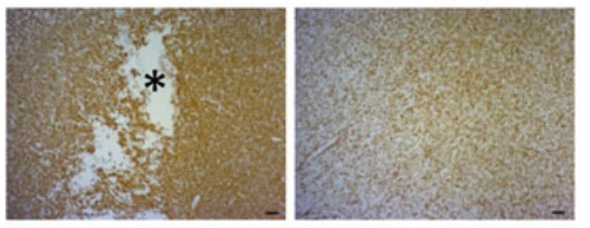

$*$
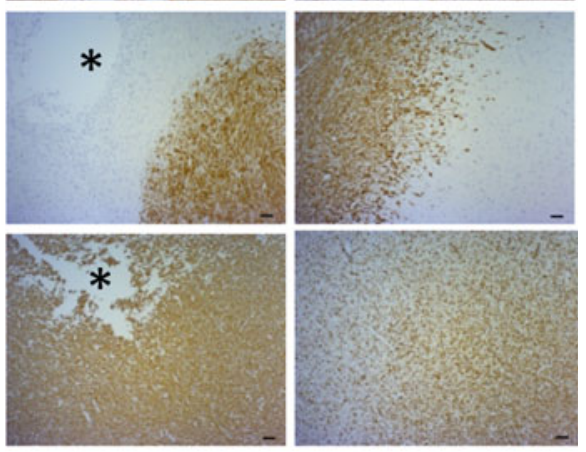

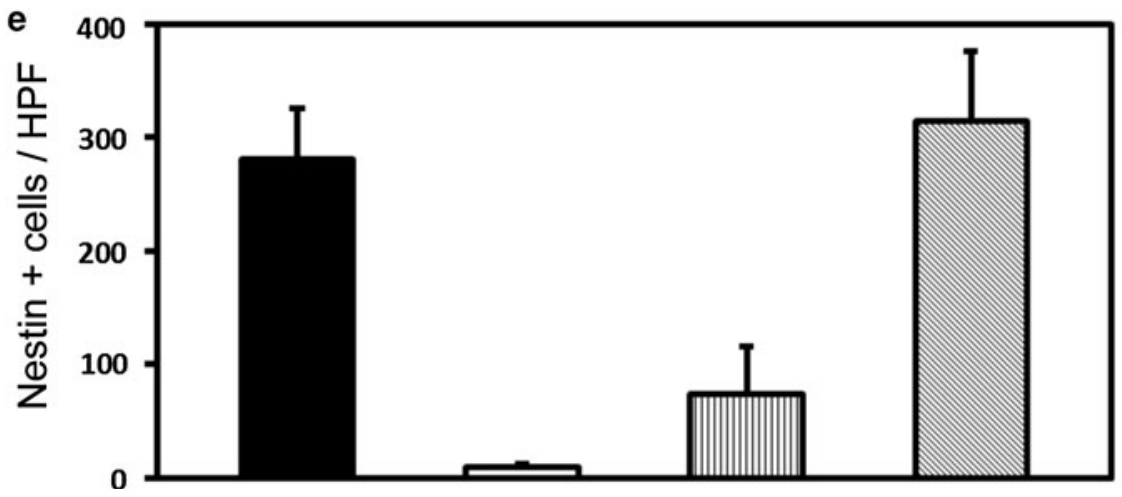

Control Distal to I.S.

Cetuximab Proximal to I.S.

Cetuximab Distal to I.S.

Two Weeks Post Cetuximab

Distal to I.S.

Fig. 4 Cetuximab inhibits growth and invasion of EGFR-amplified tumors. EGFR-amplified xenograft tumors (P8) were treated with cetuximab intracerebrally for 4 weeks using osmotic mini-pumps 6 weeks after tumor implantation. a T2- and T1-weighted MRIs of control and treated tumors with and without contrast. Treated tumors are smaller compared to control tumors. b Quantification of tumor volumes from MRI pictures. $P<0.001, n=3$ (controls), $n=4$ (cetuximab). Values represent mean \pm SD. c Quantification of proliferating tumor cells from Ki67 immunostained sections at $\times 400$ magnification. $P<0.001, \quad n=10$. Values represent mean \pm SD. d Immunohistochemical staining with antibodies against human-specific nestin, used as a tumor cell marker. Asterisk marks the injection site (IS). Scale bars $100 \mu \mathrm{m}$. e Quantification of invasive, nestin positive tumor cells. HPF high microscopic view field $(\times 400$ magnification). $P<0.001$ except: cetuximab proximal to IS versus cetuximab distal to IS, $P<0.01$ and control versus 2 weeks post cetuximab, $P=0.196 ; n=10$. Values represent mean $\pm \mathrm{SD}$ 
a

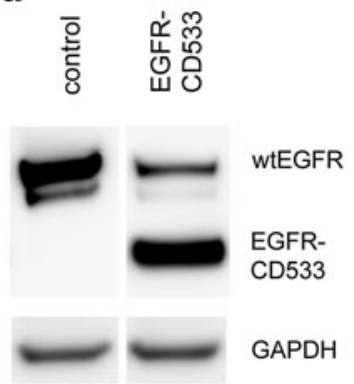

b

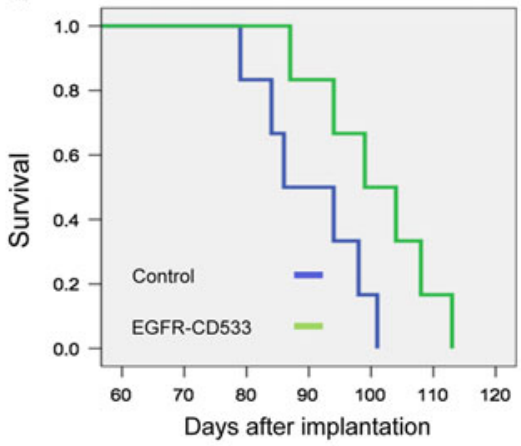

C

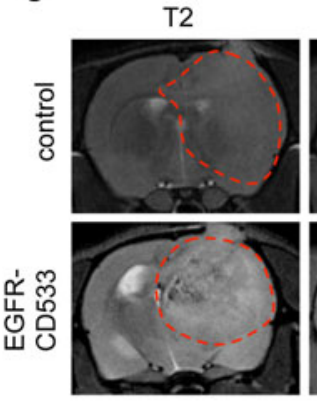

T1

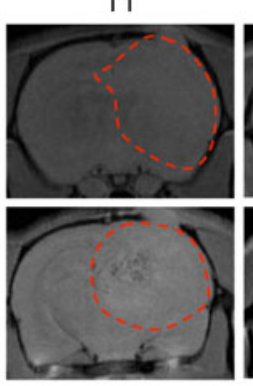

T1 w/contrast

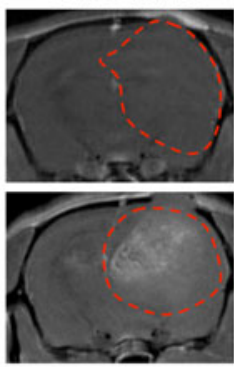

d

Macroscopy

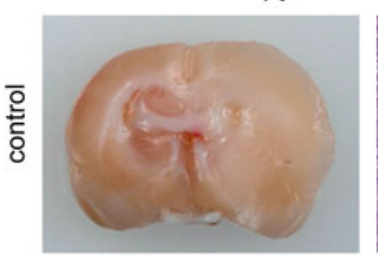

$\mathrm{H} \& \mathrm{E}$
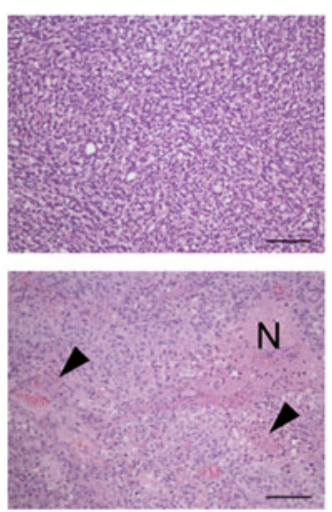

f
pEGFR
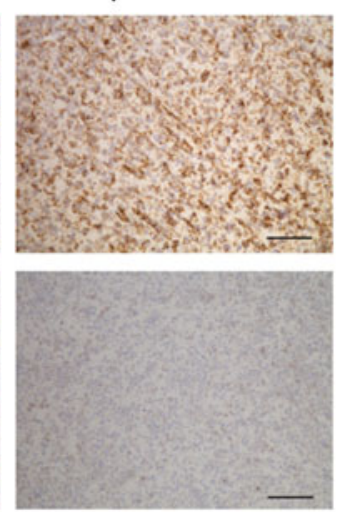

vWF
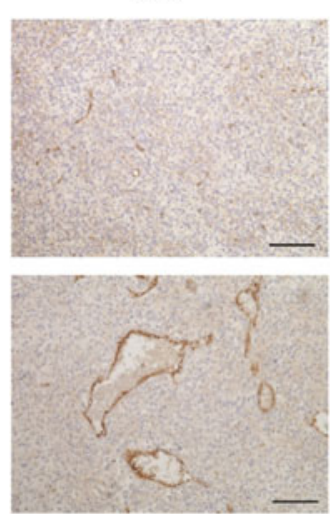

Pimonidazole
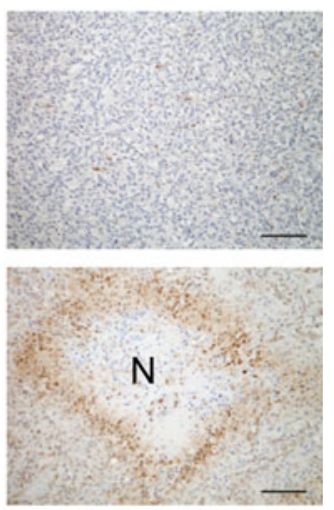

e

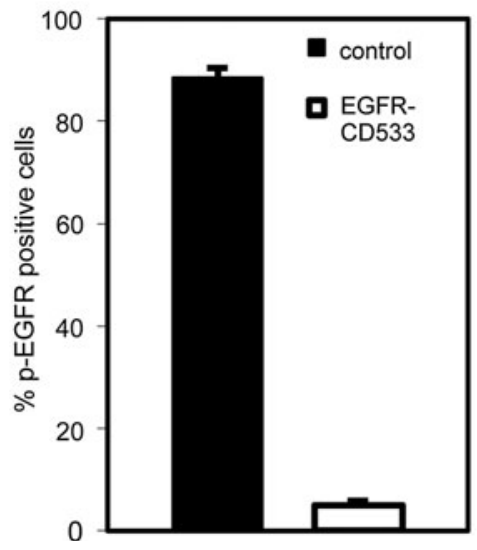

g
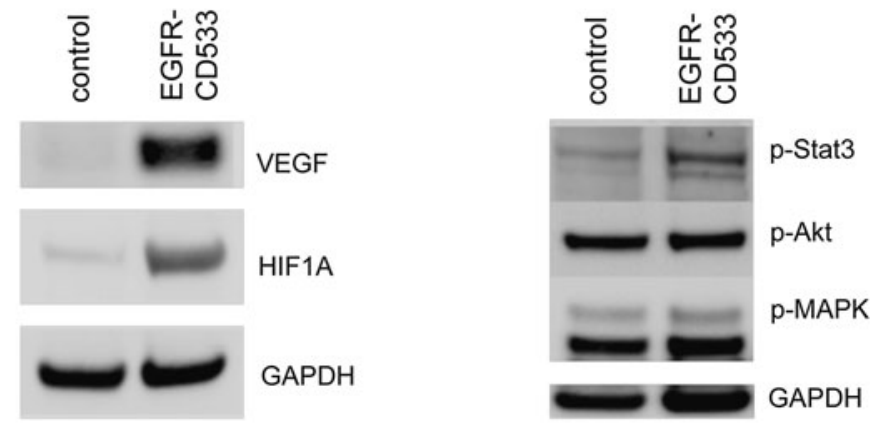

Fig. 5 Stable expression of EGFR-CD533 induces an angiogenic switch in EGFR-amplified tumors. Tumor spheroids from EGFRamplified tumors (P8) were mock infected or infected with lentiviral vectors carrying EGFR-CD533. Infected spheroids were implanted into the brain of nude rats. a Western blot of a control tumor and a tumor transduced with EGFR-CD533 with antibodies against EGFR. b Kaplan-Meier survival curve of EGFR-CD533 and control tumors. The difference in survival is statistically significant (log-rank; $P<0.05)$. c T2- and T1-weighted MRIs with and without contrast show more demarcated tumors with contrast enhancement in the EGFR-CD533 group, while the control tumors have ill-defined borders and are devoid of contrast enhancement. d Macroscopic,

at the macroscopic and microscopic level. Angiogenic growth was clearly evident in the EGFR-CD533 tumors, which were circumscribed and harbored microvascular coronal view of rat brains with control and EGFR-CD533 tumors. $H \& E$ sections show non-angiogenic versus angiogenic tumor growth in control versus EGFR-CD533 tumors. Immunohistochemical staining with antibodies against pEGFR, vWF and pimonidazole, a marker for hypoxia. $N$ depicts necrotic areas and the arrowheads indicate microvascular proliferation. Scale bars $100 \mu \mathrm{m}$. e Quantification of pEGFR positive cells in tumors from two different animals in each group. Quantification was performed at $\times 400$ magnification. $P<0.001 ; n=10$. f Western blot with antibodies against HIF1A and VEGF. g Western blot with antibodies against pStat3, pAkt and pMAPK

proliferations and necroses. Angiogenesis was absent in the diffusely invasive growing tumors of the control group (Fig. 5d, Fig. S6). Importantly, EGFR activation (pEGFR) 

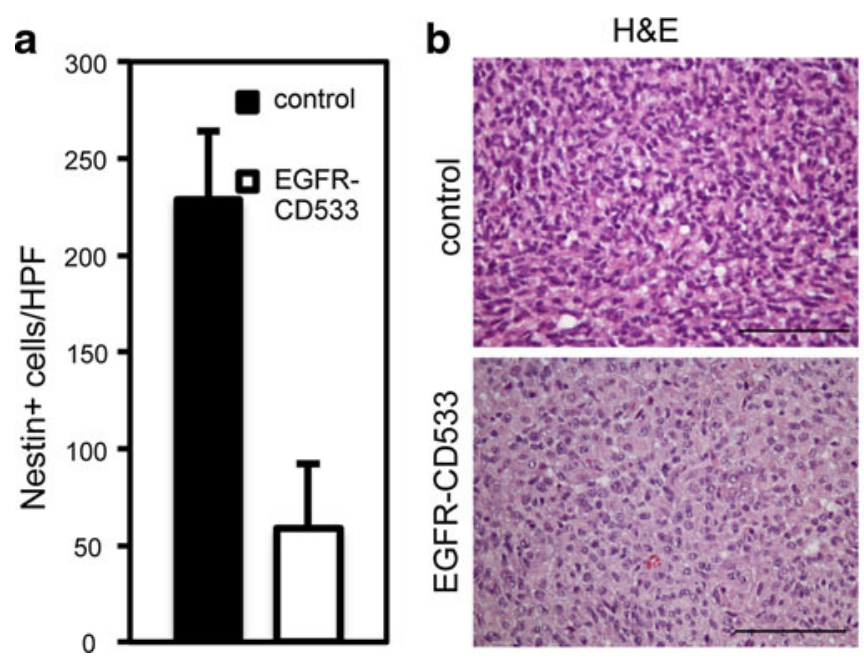

Fig. 6 Expression of EGFR-CD533 promotes a mesenchymal to epithelial-like transition in EGFR-amplified tumors. a Quantification of invasive cells in cortical areas from two different animals in each group. $H P F$ high microscopic view field $(\times 400$ magnification $)$. Asterisk $P<0.001 ; n=10$. Values represent mean $\pm \mathrm{SD}$.

was significantly inhibited in the EGFR-CD533 tumors compared to the control tumors (Fig. 5d, e, Fig. S6).

To determine whether the tumors were hypoxic, pimonidazole staining was performed. While hypoxic areas were identified around necroses in the EGFR-CD533 group, no hypoxic regions were observed in control tumors (Fig. 5d). We further determined the expression of HIF1A and VEGFA to verify induction of an angiogenic switch at the molecular level. Upregulation of HIF1A and VEGFA occurred in the EGFR-CD533 transduced, angiogenic tumors whereas both proteins were absent/less expressed in the control tumors (Fig. 5f, Fig. S6). Functional analysis of gene expression data using Ingenuity Pathway Analysis (IPA) showed that the biological function "angiogenesis" was highly enriched ( $\left.p 2.22 \times 10^{8}\right)$ in the dataset. $Z$ score analysis revealed that angiogenesis was significantly increased ( $z$ score 3,305 ) in EGFRCD533 tumors (Table S3). Subsequently, we used IPA to query for significantly altered upstream regulators in the dataset. HIF1A was the top enriched upstream regulator $\left(P 3.45 \times 10^{11}\right.$; Fig. S7).

To analyze whether inhibition of EGFR activation affected major downstream signaling pathways, we performed western blots for phosphorylated Akt, MAPK and Stat3. While Akt and MAPK activation were not changed, phosphorylation of Stat3 was enhanced in the EGFRCD533 group (Fig. 5g). Thus, major downstream signaling was not blocked by inhibiting EGFR activation which is in line with previous clinical studies using EGFR inhibitors $[24,33,41]$ and might in part explain the resistance to antiEGFR therapy.

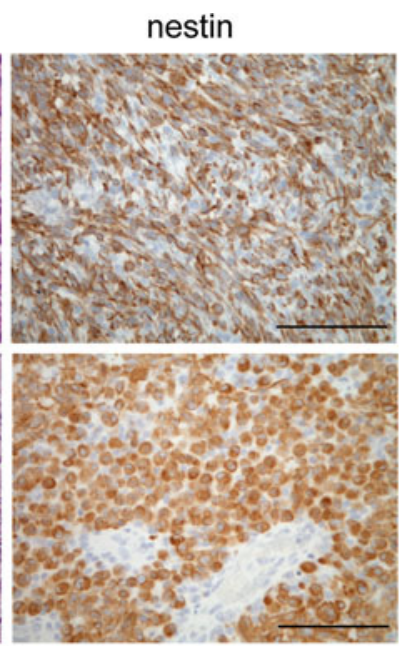

C
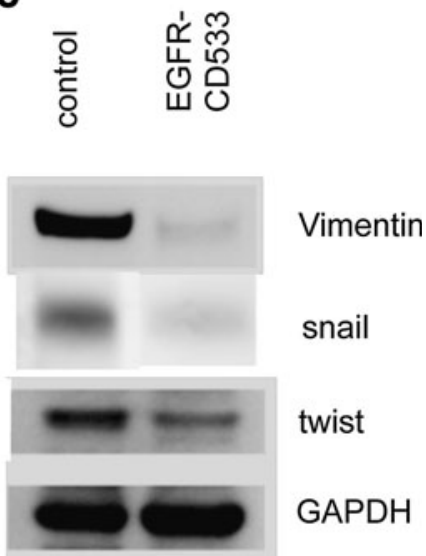

b Hematoxylin and eosin $(\mathrm{H} \& \mathrm{E})$ and immunohistochemical staining against nestin show mesenchymal shape of cells in control versus epithelial-like shape in EGFR-CD533 tumors. Scale bars $100 \mu \mathrm{m}$. c Western blot with antibodies against vimentin, snail and twist

Stable inactivation of EGFR induces a mesenchymal to epithelial-like transition in EGFR-amplified xenografts

To verify that inhibition of EGFR activity affected the invasiveness of tumor cells, we performed detailed cell counts, which revealed less invasive cells in cortical areas within the EGFR-CD533 group compared to the control group (Fig. 6a, Fig. S6). Loss of invasiveness and cell motility is often accompanied by changes in morphology, also referred to as mesenchymal to epithelial transition (MET) [26]. In the EGFR-CD533 group, histology and nestin staining showed tumor cells with an epithelial-like phenotype compared to mesenchymal control cells (Fig. 6 b). MET was confirmed at the molecular level by analyzing vimentin, snail and twist expression, which are established markers for mesenchymal tumor cells and are upregulated upon epithelial to mesenchymal transition as well as during the metastatic process of epithelial cancers [8, 61]. Vimentin, snail and twist were all strongly downregulated in EGFR-CD533 tumors as compared to controls (Fig. 6c).

\section{Discussion}

In summary, our data show that tumor cell invasion is strongly associated with wtEGFR amplification and activation and that this process is independent of angiogenesis in human GBMs. The selection for EGFR amplification in our animal model, the coincidence of wtEGFR expression and invasion as an early process in tumorigenesis, and the 
stem-like properties of these cells described previously [53] suggest a functional role for wtEGFR in cancer development. This is supported by a recent study, demonstrating the importance of wtEGFR for tumor development and invasive growth within a stem-like human GBM xenograft model [40]. Taken together, this study and our results show that the non-angiogenic wtEGFR-amplified population clearly represents a different subset of cancer cells as compared to the highly angiogenic cancer stem-like cells, which have been proposed to be the only tumorigenic cells within GBMs [2, 20, 32, 55].

Although the inhibition of EGFR activation significantly reduced tumor growth and invasion in our model, tumor cells had the capacity to induce an angiogenic program and thereby escape the invasion block as shown by stable expression of dominant-negative EGFR. In this experimental set-up, we observed a mesenchymal to epitheliallike transition, which might explain the inability of EGFRCD533 expressing tumor cells to escape from hypoxic areas through invasion and instead induce an angiogenic program by upregulating HIF1A. This was verified by a microarray analysis showing that genes which are transcriptionally activated by HIF1A were upregulated in the EGFR-CD533 expressing tumors. Recently, Lu et al. [35] observed that c-Met induced an epithelial to mesenchymal transition and invasive phenotype after VEGF inhibition in glioblastoma. This indicates that in addition to EGFR other tyrosine kinase receptors might be important for invasion and a mesenchymal phenotype in high-grade glioma. In contrast, low grade gliomas often do not show amplification of tyrosine kinase receptors [16], but are also invasive. Thus, in these tumor types other mechanisms driving tumor invasion might be responsible.

Our results highlight the dynamic nature of highly malignant tumor cells that have a number of genetic changes in common such as $9 p$ and $10 \mathrm{q}$ deletions that disrupt PTEN, p53 and RB tumor suppressor pathways $[9,49]$. The inactivation of these pathways is probably sufficient to drive tumor growth as also verified in genetic mouse models of GBMs [1, 62]. Inactivation of these tumor suppressor genes may also activate major downstream signaling events such as AKT, MAPK and Stat3 which, as shown in the present study, is not dependent on wtEGFR activation; however, the EGFR status as demonstrated here has an important impact on the balance between invasive and angiogenic tumor growth. In particular, patient tumors are highly heterogenous and contain both, cells with and without EGFR amplification. Cells with high $E G F R$ amplification are more frequent in invasive areas as compared to the main angiogenic tumor mass $[48,54]$. Additional support has been provided in a recent study showing that the invasive areas of GBMs with coamplification of EGFR and $P D G F R$ exclusively contain
EGFR-amplified cells, while $P D G F R$ amplified cells are only found in the main tumor mass [54]. Accordingly, the angiogenic switch in human tumors might be induced by less migratory cells in which EGFR signaling is absent/ low. In this context, we showed that only a subset of EGFR-amplified tumor cells within GBM biopsies had a highly activated EGFR and importantly, these cells were found in non-angiogenic/invasive areas.

In our xenograft model system, wtEGFR was the main driver of invasion, whereas mutated EGFRvIII was lost after serial passaging. In contrast, wtEGFR was downregulated in tumors that switched to an angiogenic phenotype, while EGFRvIII was stably expressed. This shows opposite regulations of wtEGFR versus EGFRvIII in our xenograft system and strong associations to either invasion or angiogenesis, respectively. Several studies have shown that EGFRvIII is responsible for angiogenic growth within GBM animal models and cell lines using overexpression approaches [6, 11, 28, 36] and that EGFRvIII differs from wtEGFR signaling [29, 44-46]. Although it has been demonstrated that wtEGFR also can induce upregulation of angiogenic factors in glioma cell lines in vitro [21, 28, 37, 52], there is lack of evidence that this can be a mechanism in vivo. In contrast, by preserving naturally occuring $E G F R$-amplified cells in vivo, we have clearly shown that wtEGFR is a driver of invasion in human GBM in vivo. The mechanism of how the gene expression of EGFRvIII and wtEGFR are regulated in our animal model and also in human GBM still needs to be identified. However, a recent study suggests that at least EGFRvIII is epigenetically regulated [15].

The EGFR-activated tumor subpopulation is an important target for therapy as these cells are highly invasive and, accordingly, have the capacity to escape current therapies. In addition, an intact BBB inherently impedes drug delivery to invasive and non-angiogenic tumor regions. In our xenograft model, we clearly demonstrate that local delivery of an anti-EGFR antibody significantly inhibits tumor growth and invasion. These results highlight the importance of anti-EGFR therapy as an anti-invasive treatment strategy for GBM and most likely also explain why systemic administration of otherwise effective antiEGFR drugs fails to show substantial effects in the clinic [41]. Although it has been postulated that small molecule inhibitors may successfully circumvent the drug penetration problem often associated with antibody therapies involving the CNS, recent observations show that drug transporters in endothelial cells of intact vessels prevent effective penetration of these molecules $[17,31,38]$. Thus, a major challenge in targeting these invasive, EGFR-activated tumor subpopulations will be to effectively deliver bioactive molecules across the BBB and at the same time inhibit potential angiogenic escape mechanisms. 
Acknowledgments We thank I. Gavlen, B. Hansen, E. Fick, L. Vårdal, E. Jensen, A. S. Herdlevær, R. Owen, S. Leh, K. Mangseth and E. Mutlu for expert technical assistance and the Molecular imaging center (MIC) in Bergen, Norway for technical support. We thank A. Muller from the Genomics Research Unit of CRP-Santé in Luxembourg for expert assistance with the use of Ingenuity Pathway Analysis. K. Talasila was supported by a $\mathrm{PhD}$ fellowship from the University of Bergen. This work was supported by the Research Council of Norway (grant 213630 to HM), The Norwegian Cancer Society, Helse Vest, Haukeland University Hospital, the Bergen Medical Research Foundation, the European Commission 6th Framework Programme (Contract 504743) and by the CORE program of the Fonds National de la Recherche (FNR) in Luxembourg (ESCAPE C10/BM/784322).

Open Access This article is distributed under the terms of the Creative Commons Attribution License which permits any use, distribution, and reproduction in any medium, provided the original author(s) and the source are credited.

\section{References}

1. Alcantara Llaguno S, Chen J, Kwon CH, Jackson EL, Li Y, Burns DK, Alvarez-Buylla A, Parada LF (2009) Malignant astrocytomas originate from neural stem/progenitor cells in a somatic tumor suppressor mouse model. Cancer Cell 15:45-56

2. Bao S, Wu Q, Sathornsumetee S, Hao Y, Li Z, Hjelmeland AB, Shi Q, McLendon RE, Bigner DD, Rich JN (2006) Stem cell-like glioma cells promote tumor angiogenesis through vascular endothelial growth factor. Cancer Res 66:7843-7848

3. Barrett T, Kobayashi H, Brechbiel M, Choyke PL (2006) Macromolecular MRI contrast agents for imaging tumor angiogenesis. Eur J Radiol 60:353-366

4. Biernat W, Huang H, Yokoo H, Kleihues P, Ohgaki H (2004) Predominant expression of mutant EGFR (EGFRvIII) is rare in primary glioblastomas. Brain Pathol 14:131-136

5. Bjerkvig R, Tonnesen A, Laerum OD, Backlund EO (1990) Multicellular tumor spheroids from human gliomas maintained in organ culture. J Neurosurg 72:463-475

6. Bonavia R, Inda MM, Vandenberg S, Cheng SY, Nagane M, Hadwiger P, Tan P, Sah DW, Cavenee WK, Furnari FB (2012) EGFRvIII promotes glioma angiogenesis and growth through the NF-kappaB, interleukin-8 pathway. Oncogene 31:4054-4066

7. Brunckhorst MK, Wang H, Lu R, Yu Q (2010) Angiopoietin-4 promotes glioblastoma progression by enhancing tumor cell viability and angiogenesis. Cancer Res 70:7283-7293

8. Cano A, Perez-Moreno MA, Rodrigo I, Locascio A, Blanco MJ, del Barrio MG, Portillo F, Nieto MA (2000) The transcription factor snail controls epithelial-mesenchymal transitions by repressing E-cadherin expression. Nat Cell Biol 2:76-83

9. Chin L, Meyerson M, Aldape KD, Bigner DD, Mikkelsen T, VandenBerg S, Kahn A, Penny R, Fergueson M, Gerhardt D, Getz G, Brennan C (2008) Comprehensive genomic characterization defines human glioblastoma genes and core pathways. Nature 455:1061-1068

10. Citri A, Yarden Y (2006) EGF-ERBB signalling: towards the systems level. Nat Rev Mol Cell Biol 7:505-516

11. Clarke K, Smith K, Gullick WJ, Harris AL (2001) Mutant epidermal growth factor receptor enhances induction of vascular endothelial growth factor by hypoxia and insulin-like growth factor-1 via a PI3 kinase dependent pathway. Br J Cancer 84: 1322-1329

12. Collins VP (1995) Gene amplification in human gliomas. Glia 15:289-296
13. Contessa JN, Reardon DB, Todd D, Dent P, Mikkelsen RB, Valerie K, Bowers GD, Schmidt-Ullrich RK (1999) The inducible expression of dominant-negative epidermal growth factor receptor-CD533 results in radiosensitization of human mammary carcinoma cells. Clin Cancer Res 5:405-411

14. De Witt Hamer PC, Van Tilborg AA, Eijk PP, Sminia P, Troost D, Van Noorden CJ, Ylstra B, Leenstra S (2008) The genomic profile of human malignant glioma is altered early in primary cell culture and preserved in spheroids. Oncogene 27:2091-2096

15. Del Vecchio CA, Giacomini CP, Vogel H, Jensen KC, Florio T, Merlo A, Pollack JR, Wong AJ (2012) EGFRvIII gene rearrangement is an early event in glioblastoma tumorigenesis and expression defines a hierarchy modulated by epigenetic mechanisms. Oncogene. doi:10.1038/onc.2012.280

16. Ekstrand AJ, James CD, Cavenee WK, Seliger B, Pettersson RF, Collins VP (1991) Genes for epidermal growth factor receptor, transforming growth factor alpha, and epidermal growth factor and their expression in human gliomas in vivo. Cancer Res 51: 2164-2172

17. Elmeliegy MA, Carcaboso AM, Tagen M, Bai F, Stewart CF (2011) Role of ATP-binding cassette and solute carrier transporters in erlotinib CNS penetration and intracellular accumulation. Clin Cancer Res 17:89-99

18. Euskirchen P, Skaftnesmo KO, Huszthy PC, Brekka N, Bjerkvig R, Jacobs AH, Miletic H (2011) NUMB does not impair growth and differentiation status of experimental gliomas. Exp Cell Res 317:2864-2873

19. Fischer W, Gustafsson L, Mossberg AK, Gronli J, Mork S, Bjerkvig R, Svanborg C (2004) Human alpha-lactalbumin made lethal to tumor cells (HAMLET) kills human glioblastoma cells in brain xenografts by an apoptosis-like mechanism and prolongs survival. Cancer Res 64:2105-2112

20. Folkins C, Shaked Y, Man S, Tang T, Lee CR, Zhu Z, Hoffman RM, Kerbel RS (2009) Glioma tumor stem-like cells promote tumor angiogenesis and vasculogenesis via vascular endothelial growth factor and stromal-derived factor 1. Cancer Res 69: $7243-7251$

21. Goldman CK, Kim J, Wong WL, King V, Brock T, Gillespie GY (1993) Epidermal growth factor stimulates vascular endothelial growth factor production by human malignant glioma cells: a model of glioblastoma multiforme pathophysiology. Mol Biol Cell 4:121-133

22. Groothuis DR (2000) The blood-brain and blood-tumor barriers: a review of strategies for increasing drug delivery. Neuro Oncol 2:45-59

23. Guillamo JS, de Bouard S, Valable S, Marteau L, Leuraud P, Marie Y, Poupon MF, Parienti JJ, Raymond E, Peschanski M (2009) Molecular mechanisms underlying effects of epidermal growth factor receptor inhibition on invasion, proliferation, and angiogenesis in experimental glioma. Clin Cancer Res 15: 3697-3704

24. Haas-Kogan DA, Prados MD, Tihan T, Eberhard DA, Jelluma N, Arvold ND, Baumber R, Lamborn KR, Kapadia A, Malec M, Berger MS, Stokoe D (2005) Epidermal growth factor receptor, protein kinase B/Akt, and glioma response to erlotinib. J Natl Cancer Inst 97:880-887

25. Holash J, Maisonpierre PC, Compton D, Boland P, Alexander CR, Zagzag D, Yancopoulos GD, Wiegand SJ (1999) Vessel cooption, regression, and growth in tumors mediated by angiopoietins and VEGF. Science 284:1994-1998

26. Hugo H, Ackland ML, Blick T, Lawrence MG, Clements JA, Williams ED, Thompson EW (2007) Epithelial-mesenchymal and mesenchymal-epithelial transitions in carcinoma progression. J Cell Physiol 213:374-383

27. Huszthy PC, Giroglou T, Tsinkalovsky O, Euskirchen P, Skaftnesmo KO, Bjerkvig R, von Laer D, Miletic H (2009) Remission 
of invasive, cancer stem-like glioblastoma xenografts using lentiviral vector-mediated suicide gene therapy. PLoS ONE 4:e6314

28. Jin X, Yin J, Kim SH, Sohn YW, Beck S, Lim YC, Nam DH, Choi YJ, Kim H (2011) EGFR-AKT-Smad signaling promotes formation of glioma stem-like cells and tumor angiogenesis by ID3-driven cytokine induction. Cancer Res 71:7125-7134

29. Johnson H, Del Rosario AM, Bryson BD, Schroeder MA, Sarkaria JN, White FM (2012) Molecular characterization of EGFR and EGFRvIII signaling networks in human glioblastoma tumor xenografts. Mol Cell Proteomics 11(12):1724-1740

30. Knights MJ, Kyle S, Ismail A (2012) Characteristic features of stem cells in glioblastomas: from cellular biology to genetics. Brain Pathol 22:592-606

31. Kodaira H, Kusuhara H, Ushiki J, Fuse E, Sugiyama Y (2010) Kinetic analysis of the cooperation of P-glycoprotein (P-gp/ Abcb1) and breast cancer resistance protein (Bcrp/Abcg2) in limiting the brain and testis penetration of erlotinib, flavopiridol, and mitoxantrone. J Pharmacol Exp Ther 333:788-796

32. Li Z, Bao S, Wu Q, Wang H, Eyler C, Sathornsumetee S, Shi Q, Cao Y, Lathia J, McLendon RE, Hjelmeland AB, Rich JN (2009) Hypoxia-inducible factors regulate tumorigenic capacity of glioma stem cells. Cancer Cell 15:501-513

33. Lo HW (2010) EGFR-targeted therapy in malignant glioma: novel aspects and mechanisms of drug resistance. Curr Mol Pharmacol 3:37-52

34. Louis D, Ohgaki H, Wiestler O, Cavenee W (2007) WHO classification of tumours of the central nervous system. IARC, Lyon

35. Lu KV, Chang JP, Parachoniak CA, Pandika MM, Aghi MK, Meyronet D, Isachenko N, Fouse SD, Phillips JJ, Cheresh DA, Park M, Bergers G (2012) VEGF inhibits tumor cell invasion and mesenchymal transition through a MET/VEGFR2 complex. Cancer Cell 22:21-35

36. Magnus N, Garnier D, Rak J (2010) Oncogenic epidermal growth factor receptor up-regulates multiple elements of the tissue factor signaling pathway in human glioma cells. Blood 116:815-818

37. Maity A, Pore N, Lee J, Solomon D, O'Rourke DM (2000) Epidermal growth factor receptor transcriptionally up-regulates vascular endothelial growth factor expression in human glioblastoma cells via a pathway involving phosphatidylinositol $3^{\prime}$ kinase and distinct from that induced by hypoxia. Cancer Res 60:5879-5886

38. Mandery K, Glaeser H, Fromm M (2012) Interaction of innovative small molecule drugs used for cancer therapy with drug transporters. Br J Pharmacol 165:345-362

39. Martens T, Laabs Y, Gunther HS, Kemming D, Zhu Z, Witte L, Hagel C, Westphal M, Lamszus K (2008) Inhibition of glioblastoma growth in a highly invasive nude mouse model can be achieved by targeting epidermal growth factor receptor but not vascular endothelial growth factor receptor-2. Clin Cancer Res 14:5447-5458

40. Mazzoleni S, Politi LS, Pala M, Cominelli M, Franzin A, Sergi Sergi L, Falini A, De Palma M, Bulfone A, Poliani PL, Galli R (2010) Epidermal growth factor receptor expression identifies functionally and molecularly distinct tumor-initiating cells in human glioblastoma multiforme and is required for gliomagenesis. Cancer Res 70:7500-7513

41. Mellinghoff IK, Wang MY, Vivanco I, Haas-Kogan DA, Zhu S, Dia EQ, Lu KV, Yoshimoto K, Huang JH, Chute DJ, Riggs BL, Horvath S, Liau LM, Cavenee WK, Rao PN, Beroukhim R, Peck TC, Lee JC, Sellers WR, Stokoe D, Prados M, Cloughesy TF, Sawyers CL, Mischel PS (2005) Molecular determinants of the response of glioblastomas to EGFR kinase inhibitors. N Engl J Med 353:2012-2024

42. Mitsudomi T, Yatabe Y (2009) Epidermal growth factor receptor in relation to tumor development: EGFR gene and cancer. FEBS J 277(2):301-308
43. Mitsudomi T, Yatabe Y (2010) Epidermal growth factor receptor in relation to tumor development: EGFR gene and cancer. FEBS J 277:301-308

44. Montgomery RB, Moscatello DK, Wong AJ, Cooper JA, Stahl WL (1995) Differential modulation of mitogen-activated protein (MAP) kinase/extracellular signal-related kinase kinase and MAP kinase activities by a mutant epidermal growth factor receptor. J Biol Chem 270:30562-30566

45. Moscatello DK, Holgado-Madruga M, Emlet DR, Montgomery RB, Wong AJ (1998) Constitutive activation of phosphatidylinositol 3-kinase by a naturally occurring mutant epidermal growth factor receptor. J Biol Chem 273:200-206

46. Moscatello DK, Montgomery RB, Sundareshan P, McDanel H, Wong MY, Wong AJ (1996) Transformational and altered signal transduction by a naturally occurring mutant EGF receptor. Oncogene 13:85-96

47. Naldini L, Blomer U, Gallay P, Ory D, Mulligan R, Gage FH, Verma IM, Trono D (1996) In vivo gene delivery and stable transduction of nondividing cells by a lentiviral vector. Science 272:263-267

48. Okada Y, Hurwitz EE, Esposito JM, Brower MA, Nutt CL, Louis DN (2003) Selection pressures of TP53 mutation and microenvironmental location influence epidermal growth factor receptor gene amplification in human glioblastomas. Cancer Res 63: 413-416

49. Parsons DW, Jones S, Zhang X, Lin JC, Leary RJ, Angenendt P, Mankoo P, Carter H, Siu IM, Gallia GL, Olivi A, McLendon R, Rasheed BA, Keir S, Nikolskaya T, Nikolsky Y, Busam DA, Tekleab H, Diaz LA Jr, Hartigan J, Smith DR, Strausberg RL, Marie SK, Shinjo SM, Yan H, Riggins GJ, Bigner DD, Karchin R, Papadopoulos N, Parmigiani G, Vogelstein B, Velculescu VE, Kinzler KW (2008) An integrated genomic analysis of human glioblastoma multiforme. Science 321:1807-1812

50. Philippidou D, Schmitt M, Moser D, Margue C, Nazarov PV, Muller A, Vallar L, Nashan D, Behrmann I, Kreis S (2010) Signatures of microRNAs and selected microRNA target genes in human melanoma. Cancer Res 70:4163-4173

51. Plate KH, Breier G, Weich HA, Risau W (1992) Vascular endothelial growth factor is a potential tumour angiogenesis factor in human gliomas in vivo. Nature 359:845-848

52. Pore N, Liu S, Haas-Kogan DA, O'Rourke DM, Maity A (2003) PTEN mutation and epidermal growth factor receptor activation regulate vascular endothelial growth factor (VEGF) mRNA expression in human glioblastoma cells by transactivating the proximal VEGF promoter. Cancer Res 63:236-241

53. Sakariassen PO, Prestegarden L, Wang J, Skaftnesmo KO, Mahesparan R, Molthoff C, Sminia P, Sundlisaeter E, Misra A, Tysnes BB, Chekenya M, Peters H, Lende G, Kalland KH, Oyan AM, Petersen K, Jonassen I, van der Kogel A, Feuerstein BG, Terzis AJ, Bjerkvig R, Enger PO (2006) Angiogenesis-independent tumor growth mediated by stem-like cancer cells. Proc Natl Acad Sci USA 103:16466-16471

54. Snuderl M, Fazlollahi L, Le LP, Nitta M, Zhelyazkova BH, Davidson CJ, Akhavanfard S, Cahill DP, Aldape KD, Betensky RA, Louis DN, Iafrate AJ (2011) Mosaic amplification of multiple receptor tyrosine kinase genes in glioblastoma. Cancer Cell 20:810-817

55. Soeda A, Park M, Lee D, Mintz A, Androutsellis-Theotokis A, McKay RD, Engh J, Iwama T, Kunisada T, Kassam AB, Pollack IF, Park DM (2009) Hypoxia promotes expansion of the CD133positive glioma stem cells through activation of HIF-1alpha. Oncogene 28(45):3949-3959

56. Stiver SI (2004) Angiogenesis and its role in the behavior of astrocytic brain tumors. Front Biosci 9:3105-3123

57. Sugawa N, Ekstrand AJ, James CD, Collins VP (1990) Identical splicing of aberrant epidermal growth factor receptor transcripts 
from amplified rearranged genes in human glioblastomas. Proc Natl Acad Sci USA 87:8602-8606

58. Wang J, Daphu I, Pedersen PH, Miletic H, Hovland R, Mork S, Bjerkvig R, Tiron C, McCormack E, Micklem D, Lorens JB, Immervoll H, Thorsen F (2011) A novel brain metastases model developed in immunodeficient rats closely mimics the growth of metastatic brain tumours in patients. Neuropathol Appl Neurobiol 37:189-205

59. Wang J, Miletic H, Sakariassen PO, Huszthy PC, Jacobsen H, Brekka N, Li X, Zhao P, Mork S, Chekenya M, Bjerkvig R, Enger PO (2009) A reproducible brain tumour model established from human glioblastoma biopsies. BMC Cancer 9:465

60. Wong AJ, Ruppert JM, Bigner SH, Grzeschik CH, Humphrey PA, Bigner DS, Vogelstein B (1992) Structural alterations of the epidermal growth factor receptor gene in human gliomas. Proc Natl Acad Sci USA 89:2965-2969

61. Yang J, Mani SA, Donaher JL, Ramaswamy S, Itzykson RA, Come C, Savagner P, Gitelman I, Richardson A, Weinberg RA (2004) Twist, a master regulator of morphogenesis, plays an essential role in tumor metastasis. Cell 117:927-939

62. Zheng H, Ying H, Yan H, Kimmelman AC, Hiller DJ, Chen AJ, Perry SR, Tonon G, Chu GC, Ding Z, Stommel JM, Dunn KL, Wiedemeyer R, You MJ, Brennan C, Wang YA, Ligon KL, Wong WH, Chin L, DePinho RA (2008) p53 and Pten control neural and glioma stem/progenitor cell renewal and differentiation. Nature 455:1129-1133 